\title{
Contratura térmica via artroscópica da articulação escapulo-umeral de cães
}

Angelica Cecilia

TATARUNAS ${ }^{1}$

Julia Maria MATERA ${ }^{1}$

Correspondência para:

Av. Prof Dr Orlando Marques de Paiva, 87

São Paulo-SP 015508-900

angelvet@usp.br

Recebido para publicação: 11/01/2006 Aprovado para publicação: 23/08/2007

1 - Departamento de Cirurgia da Faculdade de Medicina Veterinária e

Zootecnia da Universidade de São Paulo, São Paulo-SP

\section{Resumo}

O objetivo deste trabalho foi descrever e avaliar a exeqüibilidade da realização da técnica de contratura térmica na articulação escapulo-umeral (AEU) via artroscopia com o uso de bisturi de radiofreqüência em cadáveres de cães. Foram utilizadas 10 articulações escápulo-umerais. O portal artroscópico foi confeccionado em posição cranial ao processo do acrômio e o portal instrumental caudal a este, com inversão dos portais se necessário. O bisturi de radiofreqüência foi utilizado com o intuito de promover a contratura térmica do ligamento glenoumeral medial e da cápsula articular medial. Houve dificuldade para acessar a porção distal do ligamento citado, bem como a região caudal da cápsula articular medial. Ambas as estruturas denotaram diferente resposta tecidual à potência utilizada $(80 \mathrm{~W})$, com perfuração da cápsula articular na maioria das articulações. Acredita-se que a realização da técnica de contratura térmica na AEU no cão é exeqüível de ser realizada, porém a fim de minimizar possíveis complicações deve-se ainda determinar a potência mais adequada para os diferentes tecidos.

\section{Introdução}

A articulação escapulo-umeral (AEU) possui conformação esferoidal, sendo constituída pela grande e esférica cabeça do úmero e pela pequena e rasa cavidade glenóide. Apesar dos movimentos nesta articulação poderem ser em qualquer direção, predominam a flexão e a extensão. ${ }^{1} \mathrm{~A}$ estabilidade passiva da AEU é fornecida pelos ligamentos e estruturas capsulares, congruência articular, lábio glenóide, pequeno volume articular e mecanismos de aderência e coesão ${ }^{2}$, a estabilidade ativa ou dinâmica deve-se aos músculos do chamado "cuff rotator". Através de contração seletiva ou combinada, tais músculos podem aumentar a compressão glenoumeral, atuar como ligamentos dinâmicos e ainda resistir a forças de deslocamento que atuam na articulação. ${ }^{3,45}$

Em estudo realizado em cadáveres de cães com o intuito de analisar a estabilidade da AEU, Vasseur et al. ${ }^{6}$, seccionaram de maneira seletiva os tendões adjacentes à articulação, bem como os ligamentos glenoumerais lateral e medial. Os autores observaram que a secção dos tendões resultou em mínima ou nula alteração na estabilidade articular, porém a secção dos ligamentos glenoumerais medial ou lateral promoveram significativa mudança no movimento articular. ${ }^{6}$

A artroscopia tem permitido melhor diagnóstico e compreensão das afecções da AEU em cães adultos ${ }^{2,7,8,9}$, porém as opções de tratamento não foram completamente elucidadas. ${ }^{10}$ Apesar dos vários estudos publicados a respeito da luxação e subluxação desta articulação, a instabilidade discreta raramente é descrita. ${ }^{11}$ Os sinais clínicos (claudicação crônica) e radiográficos (doença articular degenerativa) da instabilidade da AEU no cão são inespecíficos ${ }^{4,5}$, porém a artroscopia é confirmativa para a afecção, com a detecção de lesão nos ligamentos glenoumerais ou ainda ruptura da cápsula articular. ${ }^{2,5}$ Esta doença acomete principalmente animais adultos de grande porte, portanto a detecção 
de instabilidade desta articulação durante o exame físico é difícil, devido a presença de considerável massa muscular. ${ }^{4,5}$

O diagnóstico artroscópico seguido da estabilização através de artrotomia medial ou lateral é a intervenção cirúrgica mais utilizada em cães portadores de luxação ou subluxação da referida articulação., ${ }^{5,12}$ O'Neill e Innes ${ }^{10}$ relataram o uso de equipamento de radiofreqüência bipolar para a realização de contratura térmica em um cão com achado artroscópico de instabilidade articular e os resultados foram satisfatórios.

A radiofreqüência pode ser usada para a ablação ou modificação da estrutura tecidual, de acordo com o grau de energia selecionado e o tempo que esta é aplicada ao tecido. ${ }^{13}$ A contratura térmica consiste na utilização de energia de radiofreqüência para encurtar as fibras colágenas dos ligamentos e da cápsula articular, com conseqüente aumento da estabilidade articular. ${ }^{14,15}$ Ainda, nesta técnica operatória, a energia térmica é utilizada a fim de produzir temperatura tecidual entre $70^{\circ} \mathrm{C}$ e $80^{\circ} \mathrm{C}$. O tecido aquecido encurta e aumenta a sua espessura, eliminando a cápsula articular excedente, que é um achado clínico comum em articulações instáveis. ${ }^{10,16}$

Têm-se estudado os efeitos mecânicos, biológicos e histológicos promovidos pelos equipamentos de laser ou radiofreqüência nas estruturas articulares. $\mathrm{O}$ calor altera todos os componentes do tecido, sacrificando células endoteliais e fibroblastos e desorganizando e aumentando o colágeno. ${ }^{17,18} \mathrm{~A}$ cicatrização da cápsula articular após a realização da exposição térmica pela radiofreqüência denota uma diminuição rápida na sua resistência nos primeiros 7 a 14 dias e, retorna a valores de pré-tratamento com restituição da aparência histológica normal em torno de 90 a 180 dias. ${ }^{15,17,19}$ Acredita-se, também, que se a articulação for submetida à carga fisiológica no período pós-operatório imediato, ocorrerá uma distensão da cápsula superior à do período pré-operatório. Portanto, é indicada a restrição de exercício nas primeiras 8 semanas de pós-operatório. ${ }^{14,15,20,21}$
O uso da técnica de contratura térmica para o tratamento da instabilidade articular em pacientes humanos ainda é bastante contraditório. Complicações oriundas da técnica consistem em lesão do nervo axilar e suas ramificações ${ }^{22,23,24}$, necrose de cápsula articular e recorrência dos sinais clínicos com alteração da qualidade tecidual para a reparação por outra técnica. ${ }^{24}$

O objetivo do presente trabalho foi descrever e avaliar a exeqüibilidade da realização da técnica da contratura térmica na AEU via artroscopia com o uso de bisturi de radiofreqüência bipolar em cadáveres de cães.

\section{Material e Método}

Foram estudadas 10 articulações escapulo-umerais (AEUs) de cinco cães que vieram a óbito no Hospital Veterinário da Faculdade de Medicina Veterinária e Zootecnia da Universidade de São Paulo.

\section{Instrumental Artroscópico}

$O$ instrumental utilizado para a artroscopia consistiu de endoscópio rígido (Karl Storz GmbH \& Co) de $2.7 \mathrm{~mm}$, comprimento de trabalho de $18 \mathrm{~cm}$ e ângulo de lente de $30^{\circ}$, cânula de alto fluxo de $4 \mathrm{~mm}$ de diâmetro, trocarte agudo e rombo e sonda. A fonte de luz fria com lâmpada de xenônio de $175 \mathrm{~W}$, cabo de fibra óptica de $3 \mathrm{~mm}$ largura e $250 \mathrm{~cm}$ de comprimento, monitor colorido, unidade de controle de câmera, cabeça da câmera e instrumental cirúrgico. A documentação do exame artroscópico foi realizada com videoimpressora (Vídeo Printer - Sony ) e/ ou filmagem (Filmadora - Sony).

$\mathrm{O}$ bisturi de radiofreqüência bipolar (Excalibur Plus PC $^{\circledR}$ - Bisturi eletrocirúrgico - ConMed Corporation) consistiu de caneta (Electrosurgical Handpiece - ConMed Corporation), placa, prolongador e lâmina.

\section{Técnica cirúrgica do exame artroscópico}

Os membros torácicos foram tricotomizados para a realização do procedimento artroscópico, bem como uma 
área de $10 \mathrm{~cm} \times 20 \mathrm{~cm}$ na face lateral da coxa para a conexão da placa do bisturi de radiofreqüência.

Os cadáveres foram colocados em decúbito lateral. A placa do bisturi de radiofreqüência foi mantida em contato com a área tricotomizada da coxa contralateral. Utilizou-se gel entre a placa e a pele do animal.

Inicialmente foram identificados os pontos anatômicos de referência da região: acrômio da escápula, tuberosidade maior do úmero e tendão do músculo infraespinhoso. Realizou-se artrocentese com auxilio de agulha hipodérmica 30x8 na porção lateral da articulação, perpendicular e entre o processo do acrômio e a cabeça do úmero, concomitante com leve tração realizada pela extremidade do membro. Uma seringa de $20 \mathrm{ml}$ com solução fisiológica foi acoplada a agulha e o líquido infundido até que se observasse resistência no embolo da seringa.

O portal artroscópico foi confeccionado em posição lateral e cranial ao processo do acrômio ${ }^{5}$. Para tal foi feita incisão cutânea de cerca de $1,0 \mathrm{~cm}$ de comprimento, com lâmina de bisturi $\mathrm{n}^{\mathrm{Q}} 15$. Optou-se pela utilização do trocarter rombo com a cânula para perfurar a cápsula articular e adentrar a articulação. Durante esta manobra realizou-se concomitante tração pela extremidade do membro. Na seqüência o trocarte foi substituído pelo artroscópio. Um equipo acoplado a um frasco de solução fisiológica de um litro foi conectado à cânula do artroscópio, servindo de via de influxo por gravidade. Inicialmente uma agulha hipodérmica 30x8 foi utilizada como portal de drenagem, em posição craniomedial.

$O$ portal instrumental foi confeccionado em posição lateral e caudal ao processo do acrômio, utilizando-se a técnica de triangulação. Uma agulha hipodérmica 30x8 foi introduzida caudal ao processo do acrômio ${ }^{5}$. Após a sua localização pelo artroscópio, fez-se incisão com bisturi de lâmina nô15 de cerca de $1,0 \mathrm{~cm}$, adjacente ao ponto de entrada da agulha, iniciando na pele e posteriormente perfurando a cápsula articular. A perfuração da porção sinovial da cápsula articular foi monitorada pelo artroscópio. O orifício do portal instrumental foi aumentado com auxilio de uma pinça hemostática a fim de facilitar a introdução da lâmina e cabo de bisturi de radiofreqüência.

Procurou-se promover a contratura térmica pelo leve contato pontual do bisturi com o ligamento glenoumeral medial e cápsula articular medial.

Avaliou-se a facilidade e/ou dificuldade de acesso às estruturas ligamento glenoumeral e cápsula articular mediais para a realização do procedimento proposto, utilizando os portais acima mencionados.

Complicações, dificuldades e quantificação macroscópica subjetiva da contratura promovida na cápsula e ligamento foram avaliadas e registradas.

\section{Resultados}

A artroscopia foi realizada em 10 AEUs de cinco cadáveres de cães pesando entre $15 \mathrm{~kg}$ e $20 \mathrm{~kg}$ (média: 21,2kg).

Os portais artroscópico e instrumental foram realizados conforme descrito, cranial e caudal ao processo do acrômio, respectivamente. Porém, a fim de otimizar o acesso à porção medial da articulação para o procedimento cirúrgico proposto os portais foram invertidos em sua função em quatro articulações $(40 \%)$.

A lâmina do bisturi de radiofreqüência utilizada foi adaptada para a função pelo fabricante. Esta teve a sua extremidade encurtada a fim de evitar o contato com as demais estruturas intra-articulares circundantes.

O ligamento glenoumeral medial apresentou-se na forma de $\mathrm{Y}$ em todas as articulações estudadas. $\mathrm{O}$ acesso as suas porções cranial e caudal para a realização da contratura térmica foi facilmente executado (Figura 1). A porção distal do ligamento implicou em maior dificuldade de abordagem com concomitante lesão iatrogênica da cartilagem articular da cabeça do úmero com o bisturi de radiofreqüência em três articulações $(30 \%)$.

A abordagem da porção medial da 


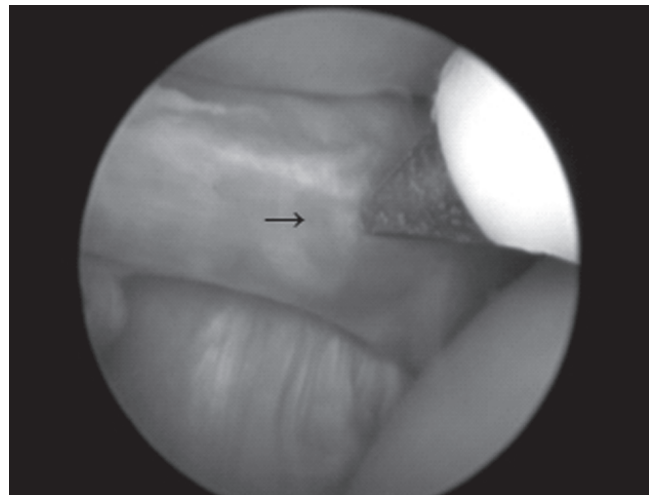

Figura 1 - Articulação escapulo umeral de cadáver de cão onde se observa a realização da contratura térmica no ligamento glenoumeral medial $(\rightarrow)$ com bisturi de radiofreqüência

cápsula articular (Figura 2), caudal ao ligamento glenoumeral medial, foi de acesso relativamente difícil para a realização da contratura térmica quando comparado à porção proximal e cranial ao ligamento, em 9 articulações (90\%).

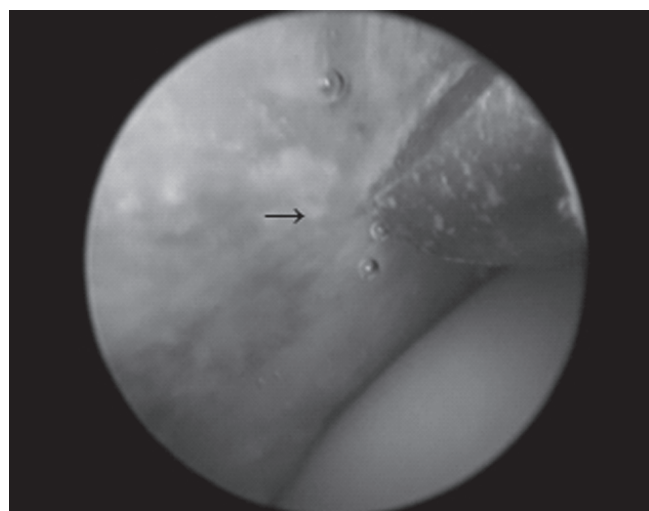

Figura 2 - Articulação escapulo umeral de cadáver de cão onde se observa a realização da contratura térmica na cápsula articular medial $(\rightarrow)$ com bisturi de radiofreqüência

Utilizou-se a potência de $80 \mathrm{~W}$ para a realização da contratura térmica de ambas as estruturas: ligamento e cápsula articular. O contato do bisturi com o ligamento glenoumeral medial foi por cerca de 2-3 segundos, pontual e superficialmente, havendo o aparecimento de coloração rósea no local de contato (Figura 3). O aumento da pressão e/ou tempo de contato promoveu o aparecimento de perda de continuidade do tecido, o qual ocorreu em 3 articulações (30\%) (Figura 4).

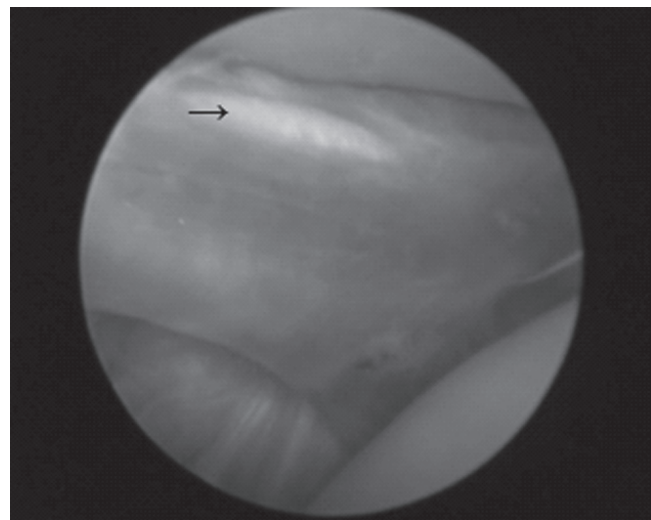

Figura 3 - Articulação escapulo umeral de cadáver de cão onde se observa alteração no aspecto do ligamento glenoumeral medial $(\rightarrow)$ após a realização da contratura térmica

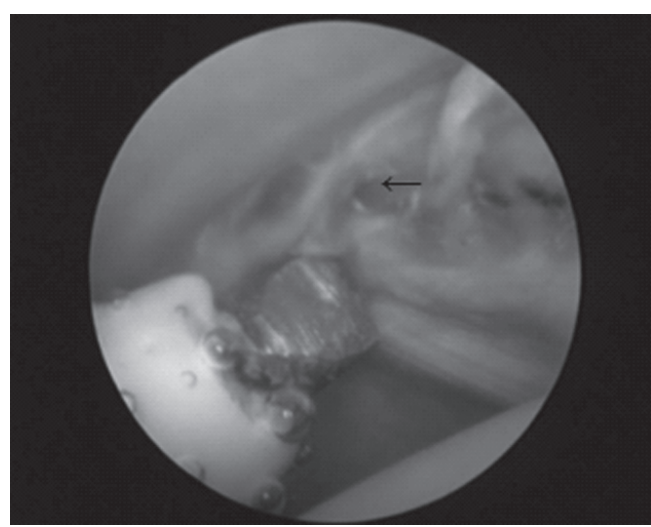

Figura 4 - Articulação escapulo umeral de cadáver de cão onde se observa ligamento glenoumeral medial $(\leftarrow)$ após realização da contratura térmica queimadura com perda de continuidade do tecido $\rightarrow$

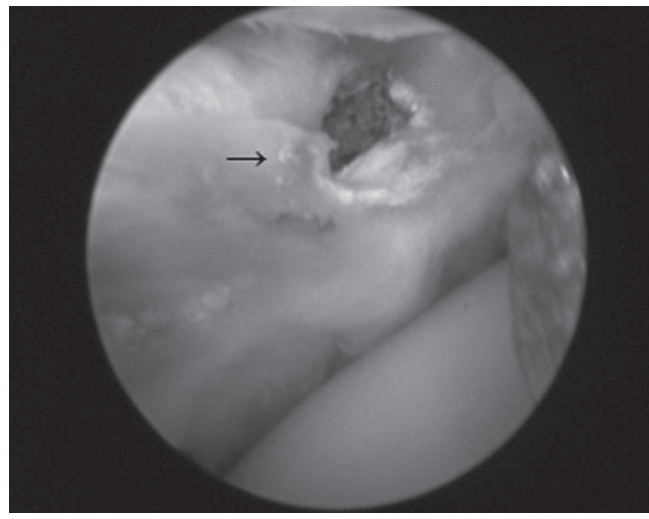

Figura 5 - Articulação escapulo umeral de cadáver de cão onde se observa cápsula articular medial com perfuração $(\rightarrow)$, após a realização de contratura térmica com bisturi de radiofreqüência 
A cápsula articular mostrou-se mais suscetível à lesão tecidual do que o ligamento glenoumeral medial sob a mesma técnica de aplicação. Em nove articulações (90\%) ocorreu perfuração da cápsula articular sendo intensa em seis (60\%) (Figura 5).

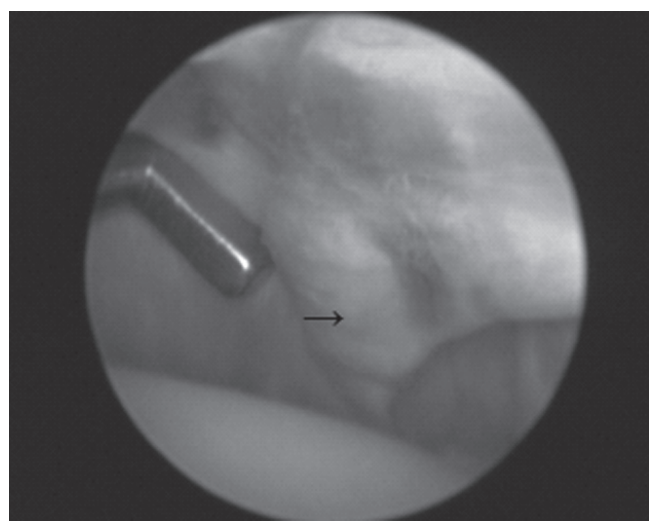

Figura 6 - Articulação escapulo umeral de cadáver de cão onde se observa ligamento glenoumera medial $(\rightarrow)$ após realização da contratura térmica, com perda de maleabilidade e irregularidade de superfície, observada pelo uso do probe

Após a realização da contratura térmica observou-se, através de palpação com o probe, alteração tanto na superfície como na maleabilidade do ligamento glenoumeral e cápsula articular mediais, com endurecimento e irregularidades superficiais (Figura 6).

Em três articulações (30\%) houve o destacamento da extremidade do bisturi do cabo de prolongamento, no interior da articulação, havendo a necessidade da sua remoção via artroscopia.

\section{Discussão}

No homem, o tratamento cirúrgico da instabilidade da AEU visa restabelecer a estabilidade com a menor morbidade ao paciente. Para tal é necessário direcionar a terapêutica para a lesão causal da instabilidade, a qual deve ser bem definida., ${ }^{3,19}$ A contratura térmica é uma modalidade terapêutica a qual tem sido amplamente estudada e empregada para o tratamento desta afecção no homem. ${ }^{15,20,21,23,25}$ A contratura térmica quando realizada por via artroscópica é uma cirurgia minimamente invasiva, a qual é aplicada diretamente sobre a estrutura lesionada, após a sua identificação.

Os autores têm chamado a atenção para a presença da instabilidade da AEU na espécie canina. Eles têm salientado a importância do exame físico associado ao exame artroscópico para a detecção de lesões sugestivas da afecção, como a ruptura parcial ou total dos ligamentos glenoumerais lateral ou medial e da cápsula articular., 2,4,5,8,9,10,11,12

Os cadáveres são modelos experimentais utilizados com freqüência para o treinamento e avaliação de técnica artroscópica tanto em medicina humana como veterinária..$^{6,16,22}$ McCarthy et al. ${ }^{22}$ referem algumas limitações para o seu uso quando do estudo da técnica de contratura térmica. Alguns fatores como a temperatura corpórea semelhante à temperatura ambiente, ausência de sangue circulante, o qual poderia dispersar o potencial de calor gerado pelo equipamento e diferenças nas propriedades de encurtamento entre o tecido morto e o vivo poderiam modificar os resultados obtidos in vivo. ${ }^{22}$ Concordamos com a afirmação do autor, porém, acredita-se que no estudo da técnica operatória proposta, o modelo se mostrou satisfatório e foi importante a boa condição de preservação do cadáver.

No cão, a técnica de contratura térmica via artroscopia é assunto recente ${ }^{5,10}$ e carece de informações quanto à localização dos portais, dados sobre o equipamento de radiofreqüência, potência, tempo e modo de aplicação. Durante este experimento foram feitas duas adaptações para o bisturi de radiofreqüência: diminuir o tamanho da lâmina e utilizar um prolongador entre a lâmina e o cabo do bisturi, ambos fornecidos pelo fabricante. O menor tamanho da lâmina minimizou a lesão às estruturas adjacentes e o prolongador permitiu o acesso à porção medial da articulação.

Enquanto O'Neill e Innes ${ }^{10}$ utilizaram o portal lateral e craniolateral para o artroscópio e instrumental, respectivamente para realizar contratura térmica na porção cranial e medial da articulação de um cão ${ }^{10}$, 
Beale et al. ${ }^{5}$ sugerem os portais lateral e cranial ao processo do acrômio para o artroscópio e lateral e caudal ao processo do acrômio para o instrumental ${ }^{5}$, como realizado neste estudo. Devido à dificuldade da realização da contratura térmica na porção distal do ligamento glenoumeral medial e na cápsula articular caudal a este ligamento pela técnica acima, realizou-se ainda a inversão dos portais, porém ainda sem resultados completamente satisfatórios.

No homem, a técnica da contratura térmica tem importante indicação para o tratamento da instabilidade da AEU, sendo descritas principalmente complicações oriundas de casos clínicos. ${ }^{14,20,22,23,24} \mathrm{Em}$ nosso estudo houve lesão iatrogênica da cartilagem articular da cabeça do úmero durante a abordagem da porção mais distal do ligamento glenoumeral medial e a liberação da lâmina do bisturi do prolongador no interior da articulação. $\mathrm{O}$ equipamento de radiofreqüência utilizado neste estudo foi adaptado daquele usado no homem e, acreditamos que a ponteira utilizada, bem como o cabo prolongador, possuíam dimensões relativamente grandes para a articulação do cão, dificultando as manobras de deslocamento e aumentando a probabilidade da ocorrência da lesão iatrogênica.

A ação do calor gerado pelo equipamento de radiofreqüência no tecido depende do grau de energia e do tempo de contato. ${ }^{13,14,15,18,17}$ Estipulamos uma potência de $80 \mathrm{~W}$ e um tempo de contato necessário para se observar alteração de coloração e / ou consistência no tecido ${ }^{10}$, porém sem promover a ruptura. Apesar de obter-se um tecido de consistência mais firme e coloração rósea na grande parte dos ligamentos tratados, houve a perfuração de quase todas as articulações quando a mesma técnica foi utilizada na cápsula articular, denotando também uma variabilidade tecidual na resposta ao calor gerado pelo equipamento de radiofreqüência.

\section{Conclusões}

A técnica de contratura térmica na AEU do cão é exeqüível, porém a fim de minimizar possíveis complicações, deve-se ainda determinar a potência mais adequada para os diferentes tecidos, bem como equipamento mais apropriado para a espécie.

\section{Arthroscopic thermic contracture of the shoulder joint in dogs}

\section{Abstract}

The aim of this paper was to describe and to evaluate the feasibility of the shoulder arthroscopic thermic contracture technique using radiofrequency scalpel in dog cadavers. Then shoulders were used. The arthroscopic portal was done cranially to the acromial process and the instrumental portal was done caudally to it. The radiofrequency scalpel was used to promote the thermic contracture of the glenoumeral medial ligament and medial joint capsule. The distal part of the mentioned ligament, as well as the caudal part of the medial joint capsule was difficult to access with the radiofrequency scalpel. The tissue reaction with the potency used (80W) was different for the ligament and joint capsule. There was perforation of the joint capsule on the majority of the studied joints. The thermic contracture technique of the shoulder is possible to be done in dogs, but more appropriate potency for the different tissues has to be determined.
Key Words:

Arthroscopy.

Scapulohumeral. Shoulder. Instability. Subluxation. Surgery. 


\section{Referências}

1 EVANS, H. E.; CHRISTENSEN G. H. Miller's anatomy of the dog. Philadelphia: WB Saunders, 1979. p. 241243.

2 BARDET, J. F. Diagnosis of shoulder instability in dogs and cats: a retrospective study. J Am Anim Hosp Assoc, v. 34, n. 1, p. 42-54, 1998.

3 LIPPITT, S.; MATSEN, F. Mechanisms of gleno-humeral joint stability. Clin Orthop, v. 291, n. 18, p. 20-28, 1993.

4 BARDET, J. F. Shoulder diseases in dogs. Vet Med, v. 97, n. 12, p. 909-918, 2002.

5 BEALE, B. S. et al. Small animal arthroscopy, Philadelphia: WB Saunders, 2003. 229 p.

6 VASSEUR, P. B. et al. Stability of the canine shoulder joint: an in vitro analysis. Am J Vet Res, v. 43, n. 2, p. 352-355, 1982.

7 VAN RYSSEN, B.; VAN BREE, H. J. J.; VYT, P. Arthroscopy of the shoulder joint in the dog. J Am Anim Hosp Assoc, v. 29, n. 2, p. 101- 105, 1993.

8 MITCHELL, R. A; INNES, J. F. Lateral glenohumeral ligament rupture in three dogs. J Sm An Pract, v. 41, n. 13, p. 511-514, 2000.

9 VAN RYSSEN, B. et al. Small Animal Arthroscopy. In: SLATTER, D. Textbook of small animal surgery. 3. ed. Philadelphia: W. B. Saunders, 2003. p. 2285-2312.

$10 \mathrm{O}^{\prime}$ NEIL, T.; INNES, J. F. Treatment of shoulder instability caused by medial glenohumeral ligament rupture with thermal capsulorrhaphy. J Sm An Pract, v. 45 , n. 10 , p. 521-524, 2004.

11 FITCH, R. B. et al. Clinical evaluation of prosthetic medial glenohumeral ligament repair in the dog (ten cases). Vet Comp Orthop Traumatol, v. 14, n. 4, p. 222-228, 2001.

12 PIERMATTEI, D. L.; FLO, G. L. The shoulder joint. In: . Brinker, Piermattei, and Flo's handbook of small animal orthopedics and fracture repair. 3. ed. Philadelphia: W. B. Saunders, 1997. p. 228-260.

13 SHELLOCK, F. G. Radiofrequency energy-induced heating of bovine capsular tissue: temperature changes produced by bipolar versus monopolar electrodes. Arthroscopy, v. 17, n. 2, p. 124-131, 2001.

14 HAYASHI, K.; MARKEL, M. D. Thermal modification of joint capsule and ligamentous tissues. Oper Tech Sports Med, v. 6, n. 3, p. 120-125, 1998.

15 MEDVECKY, M. J. et al. Thermal capsular shrinkage: basic science and clinical applications. Arthroscopy, v. 17, n. 8, p. 624-635, 2001.

16 SPEER, K. P. Anatomy and pathomechanics of shoulder instability. Clin Sports Med, v. 14, n. 8, p. 751-760, 1995.

17 HAYASHI, K. et al. Histologic evaluation of the glenohumeral joint capsule after the laser-assisted capsular shift procedure for glenohumeral instability. Am J Sports Med, v. 27, n. 2, p. 162-167, 1999.

18 LOPEZ, M. J. et al. The effect of radiofrequency energy on the ultrastructure of joint capsular collagen. Arthroscopy, v. 14, n. 5, p. 495-501, 1998.

19 MCFARLAND, E. G. et al. Histologic evaluation of the shoulder capsule in normal shoulders, unstable shoulders, and after failed thermal capsulorrhaphy. Am J Sports Med, v. 30, n. 23, p. 636-642, 2002.

20 LEVY, O.; WILSON, M.; WILLIAMS, H. Thermal capsular shrinkage for shoulder instability. Mid-term longitudinal outcome study. J Bone Joint Surg, v. 83B, p. 640-645, 2001.

21 FROSTICK, S. P. et al. Arthroscopic capsular shrinkage of the shoulder for the treatment of patients with multidirectional instability minimum 2-year follow up. Arthroscopy, v. 19, n. 4, p. 227-233, 2003.

22 MCCARTHY, E. C. et al. Temperature along the axillary nerve during radiofrequency-induced thermal capsular shrinkage. Am J Sports Med, v. 32, n. 15, p. 909-914, 2004.

23 GREIS, P. E. et al. Axillary nerve injury after thermal capsular shrinkage of the shoulder. J Shoulder Elbow Surg, v. 10, n. 4, p. 231-235, 2001.

24 WONG, K. L.; WILLIAMS, G. R. Complications of thermal capsulorrhaphy of the shoulder. J Bone Joint Surg Am, v. 83, p. 151-155, 2001. Supplement 2, pt 2.

25 ROCKWOOD, C. A.; MATSEN, F. A. The shoulder Philadelphia: WB Saunders, 1990. p. 526-30. 